Aline Vilhena Lisboa

\title{
A história familiar no processo de adoecimento somático: \\ a violência em destaque
}

TESE DE DOUTORADO

DEPARTAMENTO DE PSICOLOGIA PROGRAMA DE PÓS-GRADUAÇÃO EM PSICOLOGIA CLÍNICA

Rio de Janeiro

Fevereiro de 2011 


\section{Pontificia Universidade Católica $_{\text {a }}$

Aline Vilhena Lisboa

\section{A HISTÓRIA FAMILIAR NO \\ PROCESSO DE ADOECIMENTO SOMÁTICO:}

a violência em destaque

Tese de Doutorado

Tese apresentada ao Programa de Pósgraduação em Psicologia Clínica da PUC-Rio como requisito parcial para obtenção do título de Doutor em Psicologia Clínica.

Orientadora: Terezinha Féres-Carneiro 


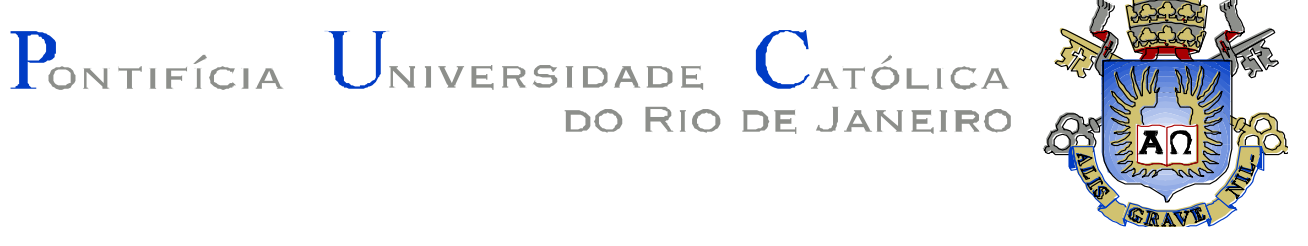

\title{
Aline Vilhena Lisboa
}

\section{A história familiar no processo de adoecimento somático: a violência em destaque}

\begin{abstract}
Tese apresentada como requisito parcial para obtenção do grau de Doutor pelo Programa de Pós-Graduação em Psicologia Clínica do Departamento de Psicologia do Centro de Teologia e Ciências Humanas da PUC-Rio. Aprovada pela Comissão Examinadora abaixo assinada.
\end{abstract}

Profa. Terezinha Féres Carneiro Orientadora Departamento de Psicologia - PUC-Rio

Profa. Andrea Seixas Magalhães Departamento de Psicologia - PUC-Rio

Profa. Edna Lucia Tinoco Ponciano UERJ

Profa. Sandra Lucia Correia Lima Fortes UERJ

Profa. Ceneide Maria de Oliveira Cerveny PUC-SP

Profa. Denise Berruezo Portinari Coordenadora Setorial de Pós-Graduação e Pesquisa do Centro de Teologia e Ciências Humanas - PUC-Rio 
Todos os direitos reservados. É proibida a reprodução total ou parcial do trabalho sem autorização da universidade, da autora e do orientador.

\section{Aline Vilhena Lisboa}

Mestre em Psicologia Clínica pela PUC-Rio em 2005 e graduada em Psicologia Clínica pela Universidade Federal de Juiz de Fora em 1999, vem realizando estudos e pesquisas na área de família e casal há mais de uma década. Especializou-se em Teorias e Técnicas Psicanalíticas ao longo de suas atividades clínicas e, hoje, é psicanalista e psicoterapeuta de família e de casal. Integra o Núcleo Interdisciplinar de Investigação Psicossomática do Departamento de Psicologia da Universidade Federal de Juiz de Fora, Minas Gerais, coordenando a linha de pesquisa Família e Psicossociossomática.

Ficha Catalográfica

Lisboa, Aline Vilhena

A história familiar no processo de adoecimento somático: a violência em destaque / Aline Vilhena Lisboa ; orientadora: Terezinha Féres-Carneiro. 2011.

229 f. : il. (color.) ; $30 \mathrm{~cm}$

Tese (doutorado)-Pontifícia Universidade Católica do Rio de Janeiro, Departamento de Psicologia, 2011.

Inclui bibliografia

1. Psicologia - Teses. 2. Família. 3. Clínica. 4. História geracional. 5. Somatização. 6. Violência. I. Féres-Carneiro, Terezinha. II. Pontifícia Universidade Católica do Rio de Janeiro. Departamento de Psicologia. III. Título. 
Ao meu marido, filhos, familiares, amigos e todas as famílias entrevistadas, que me ajudaram a crescer com esta pesquisa. 


\section{Agradecimentos}

A Deus por ter permitido que eu chegasse até aqui.

À minha querida orientadora e Professora Doutora Terezinha FéresCarneiro, amiga, parceira e sábia interlocutora, por ter acreditado mais uma vez em meu trabalho, depositando em mim a sua confiança profissional.

Ao meu marido e parceiro, Heliomar, por todo amor, companheirismo e incentivo em todas as fases deste trabalho.

Aos meus queridos filhos, Guilherme e Pedro, pela colaboração e compreensão diante dos momentos de intensa dedicação.

Aos meus pais, irmãos, cunhados, sobrinhos, parentes e amigos que se preocuparam com o meu desempenho e bem-estar, apostando na minha conquista.

À Regina Castelo Prudente que, diante dos laços da transferência, fez-se de interlocutora de minha história de vida.

Aos alunos e ex-alunos do curso de Psicologia da Universidade Federal de Juiz de Fora, Nadia Delgado, Fernanda Bassoli, Juliana Dornelas, Géssica Castellani, Rosiane Silveira, Alessandra Larcher, Vinicius Mendes e Tatiana Fernandes, que foram competentes, incansáveis e prestimosos no serviço da pesquisa.

Ao Departamento de Psicologia da Universidade Federal de Juiz de Fora que permitiu parte do desenvolvimento desta tese com os alunos do curso de Psicologia.

À Coordenação do Centro de Psicologia Aplicada e aos funcionários que testemunharam todo 0 trabalho dando 0 amparo necessário ao funcionamento do grupo de pesquisa. 
Ao Professor Doutor Almir Boechat do Departamento de Psicologia da UFJF e Coordenador do Núcleo Interdisciplinar de Investigação Psicossomática que acolheu a pesquisa, autorizando a criação da linha de pesquisa Família e Psicossociossomática, fruto desta tese.

Aos profissionais de saúde da Unidade de Atenção Primária à Saúde do Bairro de Santa Luzia em Juiz de Fora, Alfredo Claudio Paiva Maciel, Cynara Visentin de Moraes, Lucimar da Silva Possa, Marina Aparecida Tavares Silva, Reinaldo Silveira Santiago, Silvia Regina da Silva Guedes, Vera Lúcia Maria Guimarães, Sandra Maria Vieira Antonio, Rosângela Marcato Mendonça, Valéria Cristina Teodoro, Neuza Martins da Silva, que foram extremamente parceiros e compromissados no bem-fazer às famílias, facilitando todos os encaminhamentos das mesmas para a equipe de pesquisa.

À Secretaria de Saúde do Município de Juiz de Fora por ter permitido a ação da pesquisa na UAPS de Santa Luzia.

A todos os professores do Departamento de Psicologia da PUC-Rio e colegas do curso que me ajudaram a pensar sobre esta tese.

A CAPES pelo financiamento desta pesquisa.

À Marcelina e Vera pelos préstimos ao andamento do trabalho.

Enfim, às famílias entrevistadas que nos aceitaram em seus lares, confiando-nos as suas histórias de vida. 


\section{Resumo}

Lisboa, Aline Vilhena; Féres-Carneiro, Terezinha (orientadora). A história familiar no processo de adoecimento somático: a violência em destaque. Rio de Janeiro. 228 p. Tese de Doutorado. Departamento de Psicologia. Pontifícia Universidade Católica do Rio de Janeiro.

Nos últimos tempos, a família passa por transformações significativas que endossam novas formas de representação na promoção de saúde e de doença. O avanço na compreensão destes processos é tema principal desta tese, que procura ampliar as articulações possíveis entre sintomas somáticos e história familiar. O objetivo, portanto, é propor uma investigação do processo de adoecimento somático do grupo, escutando a história geracional. Utilizamos a investigação qualitativa dos dados, recorrendo à análise de conteúdo para o entendimento das representações estabelecidas sobre somatização e acontecimentos significativos da história e das fases do ciclo de vida da família. Entrevistamos dez famílias em seus domicílios por intermédio de encaminhamentos realizados pela equipe de saúde da estratégia de saúde da família do bairro de Santa Luzia, da cidade de Juiz de Fora. Durante um mês, em cada família, foram utilizados recursos técnicos como o genograma e o espaçograma, além de perguntas semidirigidas. Os dois primeiros foram montados pela equipe de pesquisa para o mapeamento de doenças e para a visualização do ambiente físico, respectivamente. De acordo com os depoimentos coletados e relatórios confeccionados, ampliamos a visão psicossociossomática do adoecimento, verificando que a doença é uma das expressões da violência familiar. A presença do alcoolismo, a repetição de comportamentos conflituosos entre gerações e a falta de apoio psíquico entre os membros exemplificam o cotidiano destas famílias. As somatizações surgem como representação da invasão do outro no corpo do sujeito, da dificuldade de expressão de sentimentos e da falta de conhecimento sobre as demandas internas da família. As lembranças de situações violentas e conflituosas geram impasses e provocam um desgaste intergeracional, fragilizando a capacidade do grupo de se manter como apoio psíquico ao outro.

\section{Palavras-chave}

Família; Clínica; História Geracional; Somatização; Violência. 


\section{Résumé}

Lisboa, Aline Vilhena; Féres-Carneiro, Terezinha (Conseiller). L'histoire de la famille dans le processus de la maladie somatique: la violence mis en évidence. Rio de Janeiro. 228 p. Thèse de doctorat. Departamento de Psicologia. Pontifícia Universidade Católica do Rio de Janeiro.

Ces derniers temps, la famille subit des transformations importantes que adoptent de nouvelles formes de représentation dans la promotion de la santé et de la maladie. Les progrès dans la compréhension de ces processus est le thème principal de cette thèse, qui vise à étendre les liens possibles entre les symptômes somatiques et histoire familial. L'objectif est donc de proposer une enquête sur le processus de la maladie somatique dans le groupe en écoutant l'histoire des générations à partir des événements significatifs et du cycle de vie. Nous avons utilisé l'investigation qualitative des données et l'analyse du contenu pour l'entendement des représentions établies sur la somatisation et les événements significatifs de l'histoire ainsi que des phases du cycle. Nous avons interviewé dix familles à leurs propre domicile aux quelles nous avons été acheminé par l'équipe de santé de la stratégie de santé de la famille du quartier de Santa Luzia, dans la ville de Juiz de Fora. Pendant un mois dans chaque famille ont été utilisés comme ressources techniques de espacegramme, de génogramme et les questions semidirigées. Les deux premières techniques ont été montés par l'équipe de recherche pour cartographier les maladies et de visualiser l'environnement physique, respectivement. Grâce aux temoignages recueillis et les rapports préparés nous avons élargi la vision psycosociossomatique de la maladie, en observant que la maladie est une expression de violence familiale. La présence de l'alcoolisme, la répétition de comportements contradictoire entre les générations et le manque de soutien psychologique entre les membres illustrent certaines de ces expressions. Les somatisations apparaissent comme une autre expression de l'invasion du corps du sujet de la difficulté à exprimer des sentiments et du manque de connaissances sur les vicissitudes de la famille. Les souvenirs des membres de la famillie provoquent un conflit intergénérationnel ainsi que la fragilité de la capacite du groupe de se mantenir comme un appui psychique à l'autre.

\section{Mots-clé}

Famille; Clinique; Histoire Générationnelle; Somatisation; Violence. 


\section{Sumário}

$\begin{array}{lr}\text { 1. Introdução } & \text { p.14 }\end{array}$

2. O Binômio Saúde-Doença p.21

2.1. As Concepções de Saúde e de Doença: breve revisão p.22

2.2. Herança Psíquica na Transmissão do Adoecimento $\begin{array}{ll}\text { Somático } & \text { p.30 }\end{array}$

2.3. Do Individual ao Familiar: fatores de risco psíquico para o $\begin{array}{ll}\text { adoecimento somático } & \text { p.36 }\end{array}$

2.4. A Psicossociossomática no Processo de Adoecimento: a construção de um novo campo de conhecimento p.42

3. A Família p.50

3.1. A História Social da Família e sua Relação com a Saúde p.52

3.2. As Fases de Vida da Família: transições, aquisições e $\begin{array}{ll}\text { impasses } & \text { p.58 }\end{array}$

3.3. A Representação da Casa e do Ambiente Familiar p.65

3.4. Fatores Desestruturantes na Família: a violência em

$\begin{array}{ll}\text { destaque } & \text { p.70 }\end{array}$

4. As Dimensões da Clínica de Família na Avaliação da Saúde p.80

4.1. A Contribuição da Psicanálise para o Trabalho Clínico com

Famílias $\quad$ p.82

4.2. A Clínica de Família e o Trabalho de Atenção Primária à $\begin{array}{ll}\text { Saúde } & \text { p.91 }\end{array}$

4.3. A Escuta de Famílias em Entrevistas Clínicas: o uso da $\begin{array}{ll}\text { interpretação e de recursos técnicos mediadores } & \text { p.97 }\end{array}$

4.4. Questões da Clínica de Família: a escuta do pré-consciente 
5. A Pesquisa e o seu Contexto

p.109

5.1. A Abordagem Qualitativa na Investigação Clínica de

Famílias

p.109

5.2. O Contexto e o Procedimento da Pesquisa: a escuta em

domicílio de famílias na comunidade de Santa Luzia em Juiz de Fora, Minas Gerais

5.3. As Entrevistas Psicológicas Domiciliares e Outros Recursos Técnicos

5.4. Família: objeto de pesquisa

p.116

5.5. Análise e Discussão dos dados socioculturais das famílias

p.118

5.5.1. Perfil Cultural e Social

p.119

5.5.2. Observações Gerais do Perfil das Famílias

p.123

5.5.3. Panorama das Doenças dos Entrevistados e de suas Gerações Anteriores

5.5.4. Panorama dos Domicílios e das Movimentações dos Membros nas Entrevistas

p.128

5.6. Análise e Discussão dos Depoimentos Coletados

5.7. História Geracional de Violência e Somatização:

compreendendo suas relações na família

6. Considerações Finais

p.194

7. Referências Bibliográficas

p.202

Anexo A Ficha de Informações Sociais e Culturais

p.218

Anexo B Roteiro de Entrevista

p.219

Anexo C Roteiro de Observação

p.220

Anexo D Termo de Consentimento Livre e Esclarecido 
Anexo E Genograma da Família 5

p.223

Anexo F Espaçograma da Família 8

p.225 
Essa coisa de família me dá chão... me dá chão firme. É de onde vem toda a tristeza e toda a alegria, de coragem de viver... ou não. 